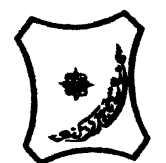

Bayero Journal of Pure and Applied Sciences, 8(1): 96 - 100

Received: January, 2015

Accepted: June, 2015

ISSN $2006-6996$

\title{
SURVEY OF GASTRO-INTESTINAL PROTOZOANS OF PIGS SLAUGHTERED AT THE JOS ABATTOIR, PLATEAU STATE, NIGERIA
}

\author{
*Gagman,H. A. **Ajayi, O. O. and ***Yusuf, A. S.
}

*Department of Biological Science, Bauchi State University Gadau, Bauchi Nigeria; **Department of Zoology, University of Jos, Nigeria, *** Department of Biological Science, Bauchi State University Gadau, Bauchi Nigeria

\begin{abstract}
An investigation on the incidence of gastro-intestinal protozoans of pigs slaughtered at the Jos Abatoir was carried out between May and November, 2007 using direct smear, floatation method and sporulation of oocysts of coccidia. Out of the 532 pigs examined 236 (44.36\%) were positive for five genera of intestinal protozoans. The study identified five genera of intestinal protozoans which include: Giardia lamblia 36(6.77\%) Isospora sp 42(7.90\%) Eimeria sp 38(7.14\%) Balantidium coli 50(9.40\%) Entamoeba sp 25(4.70\%). Mixed infection of the intestinal protozoans involving some of the five genera of the parasites recovered in this studies accounted for 45(8.46\%) out of the 532 samples. The parasites occurred more in female Pigs 148(49.66\%) than in the male pigs $88(37.61 \%)$. However statistical analysis revealed no significant difference in the sex related incidence of gastro-intestinal parasites $(P>0.05)$. Adult pigs haboured more of the parasites 282(67.14\%) than the young pigs 54(48.21\%). The incidence rate of infection for adult pigs ranged between $6.67 \%$ and $9.05 \%$ while that of young pigs ranged between $4.46 \%$ and $10.71 \%$. Statistical analysis showed significant difference in the rate of infection between the young and adult pigs at (P<0.05). The large white breed was more infected $212(44.92 \%)$ than any other breeds. Which was followed by the mixed breed $14(43.75 \%)$ and the least rate of 10(35.71\%) was recorded in the large black. Generally the incidence rate of infection with intestinal protozoans was low in this investigation as compare to previous researches.

KEY WORDS: Endemecity, Gastro-intestinal, Occurrence, Pigs, Protozoans.
\end{abstract}

\section{INTRODUCTION}

A parasite is any living organism (plant or animal) which lives inside or on the surface of another organism (the host) and from which it gains it food supply and other means of lively hood Henderson, (1990), reported that most parasites of intestinal worms are classified as cestodes (Tape worms), Trematode (flukes) nematodes (round worms) and protozoans.

It has been discovered that parasites of pigs cause major economic loss globally to pigs and pork industry and farming communities as a result of reduced feed conversion, weight gains and condemnation of affected organs after slaughter Boes et al; (2000), Joaching et al; (2001), Keshaw et al; (2009).

Pigs become infected with gastro-intestinal protozoan through oral ingestion of protozoans or their cysts from the pigs environment (pen, floors, dirty water and deep bedings). Once ingested the internal parasites go through several life cycle changes as they mature Dunne H. W. (1970). They compete with infected pigs for nutrients and may cause tissue damage Qian et al (2003), Roberts et al (2005). Pigs that are heavily infested with intestinal protozoans grow slower and are less resistant to disease and stress Ikeme et al(1970 \& 1974). The infected parts of the pigs when eaten by human, becomes potential agents of zoonotic infection Pattison $\mathrm{H}$. D. et al (1980), Weng et al (2005), Zewdneh et al; (2013).
Infection of pigs with gastrointestinal parasites is widely reported from all corners of the world and shown to be influence by the types of pig management practiced. Free range production pigs for commercial purpose is widely practice in developing countries of Africa because of availability of cost free feeds (house hall and municipal garbages) and possibilities for the animal to get better nutrition through scavenging. This made pigs famers of developing countries to prefer free range system of pig's husbandry Zewdneh et al (2013). Poor environmental hygiene couple with extensive management and free range husbandry system is reported as risk factors to infection of pigs with gastro-intestinal parasites Abdu et al (2010).

\section{AIMS AND OBJECTIVES}

This research was set up to:

$>$ Determine sex, age, and breed related rate of infection with gastro-intestinal protozoans of pigs slaughtered at the Jos Abattoir.

$>$ Identify risk factors for the infection and possible spreads of zoonoses from pigs to humans.

\section{MATERIALS AND METHODS}

Sampling Site

Samples were collected from pigs brought for slaughter at Jos Abattoir. Jos Abattoir is located in Jos South Local Government Area of Plateau State. Jos South Local Government Area is located south of Jos North between longitude $8^{0} 48^{\prime} \mathrm{W}$ and latitude $9^{0}$ $94^{\prime} \mathrm{N}$., in North Central Geo-political Zone of Nigeria. 
The headquarters is at Bukuru, which is about 15 kilometers from Jos town, the capital of Plateau State. The area is about 1,250 metres above sea level. The abattoir is a processing unit for pork hence provides job opportunity for butchers and markets for farmers (Animal breeders).

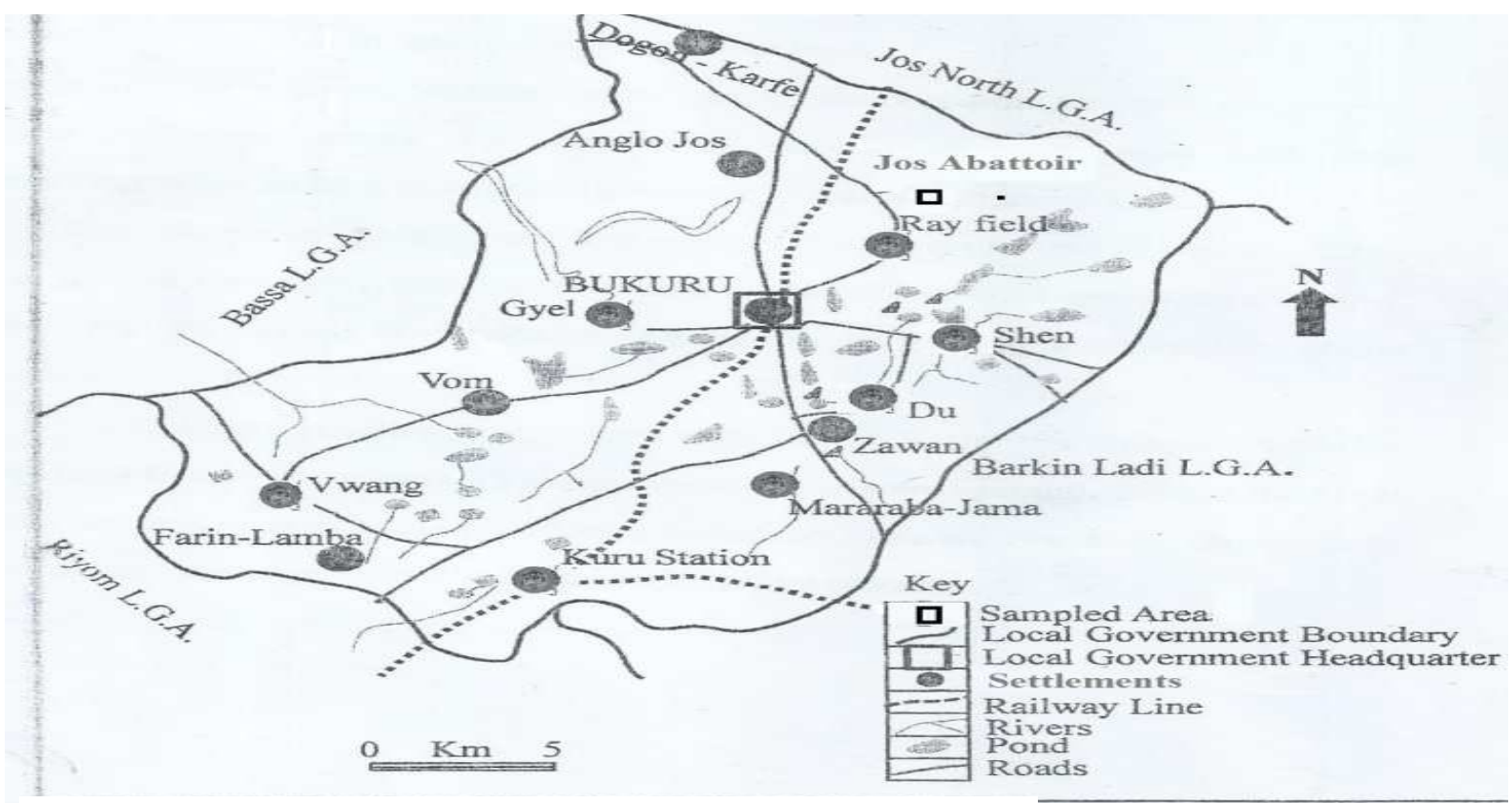

Map of Jos South Showing Jos Abattoir

\section{Faecal Samples Collection}

Faecal samples were collected base on sex, age and breeds of pigs brought for slaughter at the Jos Abattoir. Sample was collected from each pig by inserting a hand with hand glove into the rectum through the anus (Cheesbrough, 2000). About $5 \mathrm{~g}$ of the sample from each pig was immediately transferred in to screw cap specimen bottles each containing $2 \mathrm{ml}$ of $10 \%$ formalin and labeled sex, age and breed of pig and were transferred to the laboratory for analysis and examination.

\section{Analysis and Examination of Faecal Samples}

\section{$>$ Direct Smear Method}

This method was adopted from Soulsby (1986), and Cheesbrough (2000). A small quantity of the faecal sample was placed on the clean grease-free glass slide with a glass rod and a smear is made. A drop of $1 \%$ normal saline was added and thoroughly mixed. The slide was covered with a glass cover slip and examined under microscope for the presence of trophozoites and cysts of protozoans. The trophozoites and cysts were identified using keys adopted by Chandler et al(1961), Cheesbrugh (2000).

\section{$>$ Floatation Technique:-}

This was demostrated by Soulsby (1986), Sargent et al (1998), Cheesbrough (2000). About $3 g$ of faecal material was emulsified in $30 \mathrm{ml}$ of distilled water in a beaker and was filtered through sieves with mesh of 30,60, and $90 \mathrm{~mm}$. The strained material was immediately transferred into centrifuge tubes and centrifuged at 1,5000 revolutions per minute (RPM) for 5 minutes. The clear supernatant in each tube was discarded and sugar solution of specific gravity (S. G 1.2) was added to the sediment in each centrifuge tube until a convex meniscus was formed. Each tube was then covered with a glass cover slip and allowed to stand for 10 minutes. Each cover slip was then gently lifted from each tube and placed on a clean grease-free glass slide and examined under the $\times 10$ and $x 40$ objectives of the microscope for the presence of coccidian oocysts.

\section{$>$ Sporulation of Coccidian Oocysts}

This was carried out following the method of Ajayi et al, (1988). From each faecal sample, about $4 \mathrm{~g}$ was transferred into a labeled petri-dish to which about $40 \mathrm{ml}$ of $2.5 \%$ Potassium dichromate was added and then mixed thoroughly. The petri-dishes were covered with perforated aluminum foil so as to minimize evaporation and for adequate and static sporulation of any coccidian Oocysts. Slides were prepared from each sample and viewed. Two genera of coccidian oocysts namely Eimeria and Isospora spp were identified using keys adopted from Chandler et al (1961), Cheesbrugh (2000).

\section{Statistical Analysis}

A Pearson's chi-square test was used to test a correlation between occurrence of protozoans parasites with regard to age, sex and breeds of pigs. 


\section{RESULTS}

The overall rate of infection with gastro-intestinal protozoans of pigs slaughtered at the Jos Abattoir is presented in Table 1. Out of the 532 pigs examined, $236(44.36 \%)$ were infected by five genera of different protozoan parasites. The most common of the protozoan parasites recovered was $B$. coli with the infection rate of $(9.40 \%)$ this was followed by isospora sp (7.90\%), Eimeria sp (7.14\%), G. lamblia $(6.77 \%)$ and the least rate recorded was Etamoeba sp with (4.70\%). Mixed infection involving any two or more of the five genera of the protozaon parasites were recorded in $45(8.46 \%)$ out of the 532 sample examined.

Table 2 showed the sex related rate of infection with gastro-intestinal parasites of pigs slaughtered at the Jos Abattoir. The parasites were recorded more among the female pigs $148(49.66 \%)$ than the male pigs $88(37.61 \%)$. The rate of infection among the female pigs ranged between $5.03 \%$ and $10.06 \%$ while that of male ranged between $4.27 \%$ and $8.55 \%$. In female $B$. coli recorded the highest rate of 10.73 while Etamoeba sp recorded the least rate of $5.03 \%$. In male, Eimeria $s p$ has the highest prevalence rate of $8.55 \%$ and the least $4.27 \%$ was Entamoeba $s p$.

Chi square analysis revealed no significant difference in the sex related rate of infection with gastrointestinal protozoans among the pigs $(P>0.05)$.
Age related rate of infection with gastro-intestinal protozoan in pigs is presented in Table 3 . The parasites were more $282(67.14 \%)$ in adult pigs than $54(48.21 \%$ ) in piglets (young pigs). The rate of infection in adult pigs in descending order are as follows: B. coli, 38(9.05\%), Isospora sp 33(7.86\%), G.lamblia $31(7.38 \%)$, Eimeria $28(6.67 \%)$ and the least rate of $17(4.05 \%)$ was Entamoeba $s p$.

Also $B$. coli recorded the highest rate of $12(10.71 \%)$ in the piglets. This was followed by Eimeria $s p$ $10(8.93 \%)$, Isospora sp $9(8.04 \%)$, Entamoeba $s p$ $8(7.14 \%)$ and the least was G.lamblia with $5(4.46 \%)$. $10(8.04 \%)$ of the piglets haboured mixed infection while $35(8.33 \%)$ of the adults pigs harboured mixed infection. There was significant difference in the rate of infection between the piglets and the adult pigs ( $P$ $<0.05$ ).

Table 4 showed breeds-related rate of infection with gastro-intestinal protozoans. The highest rate of $44.92 \%$ was recorded among the large white, followed by $43.75 \%$ among the mixed breed and the least rate of $35.71 \%$ was recorded among the large black. Also mixed infection was recorded at $8.47 \%$, $10.71 \%$, and $6.25 \%$ among the large white, large black and mixed breeds respectively.

Table 1: Overall rate of infection with gastro-intestinal protozoans of pigs slaughtered at the Jos Abattoir.

\begin{tabular}{|c|c|c|c|c|c|c|c|}
\hline $\begin{array}{l}\text { Parasites } \\
\text { Types:- }\end{array}$ & G. Lamblia & $\begin{array}{c}\text { Isospara } \\
\text { sp }\end{array}$ & $\begin{array}{c}\text { Eimeria } \\
s p\end{array}$ & $\begin{array}{c}\text { Balantidium } \\
\text { coli }\end{array}$ & $\begin{array}{c}\text { Entamoeba } \\
s p\end{array}$ & $\begin{array}{l}\text { Mixed } \\
\text { infection }\end{array}$ & Total \\
\hline No. of pig & No (\%) & No (\%) & No (\%) & No $(\%)$ & No (\%) & No (\%) & Total (\%) \\
\hline $\begin{array}{l}\text { Examined } \\
532\end{array}$ & $\begin{array}{l}\text { Infected } \\
36(6.77)\end{array}$ & $\begin{array}{l}\text { Infected } \\
42(7.90)\end{array}$ & $\begin{array}{l}\text { Infected } \\
38(7.14)\end{array}$ & $\begin{array}{l}\text { Infected } \\
50(9.40)\end{array}$ & $\begin{array}{l}\text { Infected } \\
25(4.70)\end{array}$ & $\begin{array}{l}\text { Infected } \\
45(8.46)\end{array}$ & $\begin{array}{l}\text { Infected } \\
236(44.36)\end{array}$ \\
\hline
\end{tabular}

Table 2: Sex related rate of infection with gastro-intestinal protozoans of pigs slaughtered at the Jos Abattoir.

\begin{tabular}{|c|c|c|c|c|c|c|c|c|}
\hline $\begin{array}{l}\text { Parasites } \\
\text { Types:- }\end{array}$ & & $\underset{\text { lamblia }}{\text { G. }}$ & $\begin{array}{c}\text { Isospara } \\
\text { sp }\end{array}$ & $\begin{array}{c}\text { Eimeria } \\
\text { sp }\end{array}$ & $\begin{array}{c}\text { Balantidium } \\
\text { coli }\end{array}$ & $\begin{array}{c}\text { Entamoeba } \\
\text { sp }\end{array}$ & $\begin{array}{l}\text { Mixed } \\
\text { infection }\end{array}$ & Total \\
\hline Sex of pigs & No. of pig & No $(\%)$ & No (\%) & No (\%) & No (\%) & No (\%) & No (\%) & $\overline{\text { Total }(\%)}$ \\
\hline Examined & Infected & Infected & Infected & Infected & Infected & Infected & Infected & \\
\hline Sows & 298 & $25(8.39)$ & $28(9.40)$ & $18(6.04)$ & $32(10.73)$ & $15(5.03)$ & $30(10.06)$ & $148(49.66)$ \\
\hline Hogs/Boars & 234 & $11(4.70)$ & $14(5.98)$ & $20(8.55)$ & $18(7.69)$ & $10(4.27)$ & $15(6.41)$ & $88(37.61)$ \\
\hline
\end{tabular}

Table 3. Age related rate of infection with gastro-intestinal protozoans of pigs slaughtered at Jos Abattoir.

\begin{tabular}{|c|c|c|c|c|c|c|c|c|}
\hline \multicolumn{3}{|c|}{$\begin{array}{l}\text { Parasites Types:- } \\
\text { Entamoeba sp }\end{array}$} & \multicolumn{2}{|c|}{$\begin{array}{l}\text { G. lamblia Iso } \\
\text { Mixed infection }\end{array}$} & $\begin{array}{c}\text { spara sp } \\
\text { Total }\end{array}$ & \multirow{2}{*}{$\begin{array}{c}\text { Eimeria } \boldsymbol{s p} \\
\text { No (\%) } \\
\text { Infected }\end{array}$} & \multicolumn{2}{|c|}{ Balantidium coli } \\
\hline Age of pigs & $\begin{array}{l}\text { No. of pig } \\
\text { Examined }\end{array}$ & $\begin{array}{l}\text { No (\%) } \\
\text { Infected }\end{array}$ & $\begin{array}{r}\text { No (\%) } \\
\text { Infected }\end{array}$ & $\begin{array}{l}\text { No (\%) } \\
\text { Infected }\end{array}$ & $\begin{array}{r}\text { No (\%) } \\
\text { Infected }\end{array}$ & & $\begin{array}{l}\text { No (\%) } \\
\text { Infected }\end{array}$ & $\begin{array}{l}\text { Total } \\
\text { Infected }\end{array}$ \\
\hline $\begin{array}{l}\text { Piglet } \\
\text { (young) }\end{array}$ & 112 & $5(4.46)$ & $9(8.04)$ & $10(8.93)$ & $12(10.71)$ & $8(7.14)$ & $10(8.04)$ & $54(48.21)$ \\
\hline Adult & 420 & $31(7.38)$ & $33(7.86)$ & $28(6.67)$ & $38(9.05)$ & $17(4.05)$ & $35(8.33)$ & $282(67.14)$ \\
\hline
\end{tabular}


Table 4. Breeds related rate of infection with gastro-intestinal protozoans of pigs slaughtered at Jos Abatoir.

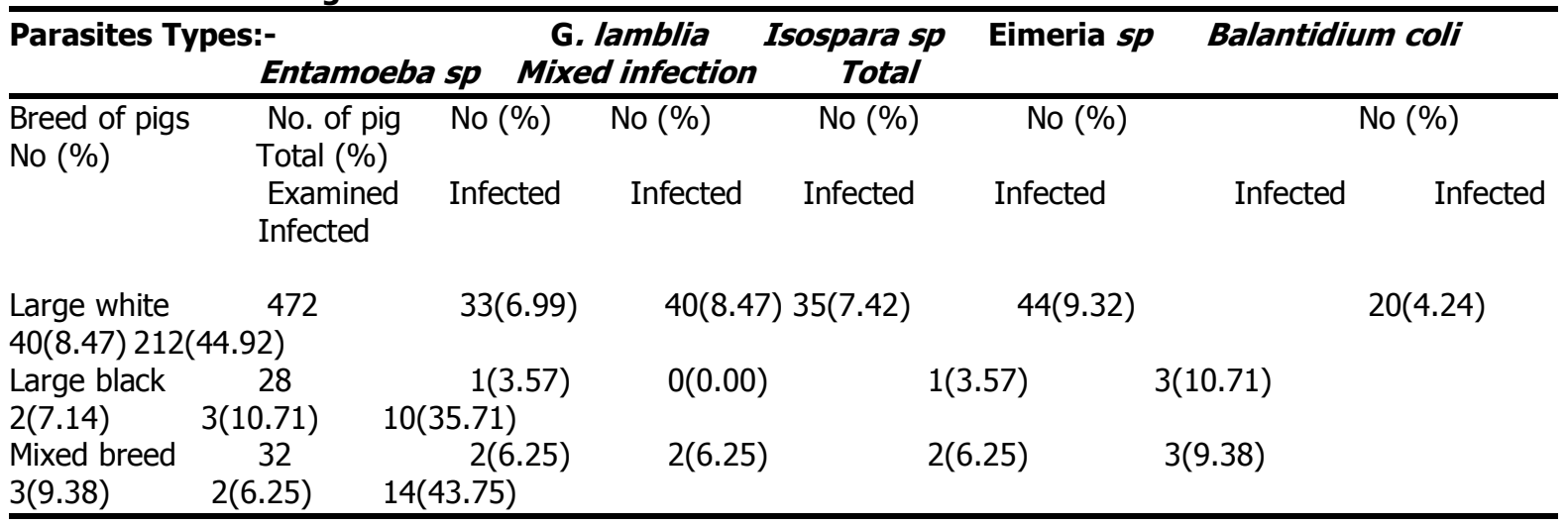

\section{DISCUSSION}

The study identified five genera of intestinal protozoans which includes G. Lamblia (6.77\%), Isospora sp $(7.90 \%)$, Eimeria sp $(7.14 \%)$, B. coli $(9.40 \%)$, and Entamoeba sp (4.70\%). This finding compares with that of Kagira et al, (2010) who identified the following protozoens parasites: Entamoeba sp (87\%), B. coli (64\%), Tricomonas suis $(42 \%)$, Eimeria sp (40\%) in Kenya. However, the rate of infection with $B$. coli, Entamoeba $\mathrm{sp}$ and Eimeria sp in this finding is lower than that of Kagira et al (2010). Kagira et al (2010) did not identified G. lamblia however, identified $T$. suis which was not identified in this study. Zewdneh et al (2013) reported G. lamblia, B. coli, Eimeria sp and Cryptosporidium sp in Ethopia, but did not identified Isospora sp and Entameoba sp as in this study. However, cryptosporidium sp was not among the protozoan parasites recorded in this study. This may be due to the methods used in this research as staining was not used because cryptosporidium $\mathrm{sp}$ can only be detected using modified ziehl-neelsen staining technique and immunofluorescence assay. Zewdneh et al (2013).

The five genera of protozoans parasites recorded in this study do not seems to be pathogenic in pigs, but pig is the source of B.coli infection in man Soulsby, (1982).

Pigs are allowed to roam about in the study area. This method of pigs husbandry could constitute a potential public health hazard in the area, especially if the pigs enter children's play area, as they may be contaminated with their faecal deposits, thus exposing children who go there to play to the risk of acquiring any of the soil transmitted protozoans of pigs Zewdneh et al (2013). Also this system of animal husbandry increase the danger of pigs infection with the soil transmitted intestinal protozoans. The epidemiology of pigs born intestinal protozoans may further be complicated when some of the protozoans of pigs infect man and vice versa Keshaw (2009).

There was significant difference in the rate of infection between the piglets (young pigs) and the adult pigs $(P>0.05)$. The young pigs haboured less of the intestinal protozoans than the adult pigs. This may be due to the fact that the adult pigs have been for long exposed to environmental garbages than the young pigs.

There was no significant difference in the sex and breeds related prevalence of protozoans infection. This may means that sexes and breeds are not factors to infection by the intestinal protozoans among pigs or the parasites have no selection on the basis of sex and breeds. Therefore, both sexes, and the various breeds have equal chance of been infected and can equally contaminate the environment and transmit the disease to man and other animals. This may be because pigs of both sex and various breeds have similar risk factors of infection with gastro-intestinal protozoans Zewdneh et al (2013). With reduction in the rate of intestinal protozoan infection, and also reducton in the variety of the genera of the parasites recorded in this study as compared to previous study, effort should be intensified on the improvement of veterinary health care, improved sanitary condition of pigs house and feeding condition as this may further reduced the rate of infection and the variety of protozoans parasites and eventually eliminating the parasites. Also free range system of pigs husbandry should be discourage back by strong legislation. This will reduced the spread of infection within the environment, among other animals and human being.

\section{CONCLUSION}

This study has revealed the existence of G. lamblia, Isopora $s p$, Eimeria $s p, B$. coli, and Entamoeba $s p$ in pigs slaughter at the Jos abattoir (2007). The rate of occurrence of protozoans parasite observed in this study was generally low but is endemic in pigs within Jos and its environs that provide the source of pigs for slaughtered in the Jos Abattoir. Sex and breeds are not factors to infection with gastro-intestinal protozoans but age.

\section{RECOMMENDATION}

$>$ Parasites control through good animal husbandry system, good and healthy feeding system, and standard veterinary health care should be adopted to improve healthy pigs production and to reduce the spread of pigs parasites and zoonitic infection among humans. 


\section{REFERENCES}

Abdu S., Gashaw A (2010) Production System Dynamism and Parasitic Interaction of swine in and around Holetta. Ethiopia, Ethiopia Veterinary Journal, 14: $71-81$

Boes, J., Willingham, A. L. Nansen, P. (2000). Prevalence and distribution of pig helminthes in Dongtin region China. Journal of Helminthology, 74: 45-52.

Cheesbrough M. (2000). District laboratory practice in tropical countries, part 2. Press sundicate of the University of Cambridge U.K Pp $320-321$.

Chandler, A. C., Read, C. P. (1961). Introduction to Parasitology. John Wiley and sons Inc. London $10^{\text {th }}$ edition pp 140-145.

Dunne H. W (1970) Diseases of swine. Iowa State University press. Third Edition pp. 708 740.

Fabiyi, J. P. (1979). Helminths of the Pig on Jos Plateau, Nigeria: relative prevalence, abundance and economic significance; Journal of Helminthology 53: 65-71.

Henderson D. C (1990), The Veterinary sheep famers. Farming press books Pp 477

Ikeme, M. M. (1970). Pig parasites of Nigeria with emphasis on the local breeds Veterinary Record 86: 684.

Ikeme, M. M., Nduaka, O. (1974). Pig parasites of Nigeria III. Local pigs industries on the Plateau area of Northern Nigeria and their helminthes problem at the peak of the rains. Bulletin of epizootic Diseases of Africa. 22: 349-335.

Joaching, A., Dulmar, N. (2001). Occurrence of helminthes in the pig fattening units with different management system in Northern Germany. Veterinary Parasitology. 9: 135146.
Kagira, J. M., Githigia, S. M., Ng'ang'a, J. C; Kanyari, P. W. N., Maingi, N. Gachohi, J. M., (2010) Prevelence of gastro-intestinal protozoan and association with risk factors in freerange pigs in Kenya. Journal of Protozooology Research 20: 1 - 9.

Keshaw P. T., Alfred C., Guillaume B., Guillaume V., Caude D., Graeme S. Ravidra N. S (2009) Prevalence of Intestinal Parasites in pigs. West Indian Veterinary Journal 9: 22-27.

Pattison, H. D; Thomas, R. D, Smith W. C. (1980). A survey of gastro-intestinal parasitism in pigs. Veterinary Record 107: 415-418.

Qian, X. Z. and Xu, Q. P. (2003). Investigation on the prevalence of coccidian in pig in the city of Taizhou, Jiangsu province, China. Journal of Veterinary Parasitology. 11 (1): 31-32.

Robert, M. C. and Rodric, C. I. (2005) Common internal parasites of swine, University of Missouri Mu Extension. 30: 1-7.

Weng, Y. B. Hu, Y. J., Li, Y., Li, B.S., Lin, D. H., Xie, Gasser, R. B., Zhu, X. Q. (2005). Survey of intestinal parasites of pigs from intensive farms in Guangdong province, people's Republic of China. Journal of Veterinary Parasitology. 127: 333-336.

Zewdneh T., Ekeal I., Tsegabirhan K., Yohannes T., Kidane W. (2013) Prevalence of gastrointestinal parasites and cryptosporidium species in extensively managed pigs in Mekelle and urban areas of southern zone of tigray region, Northern Ethiopia. Veterinary World 6: $433-439$. 